\title{
Identifying the Configurational Conditions for Marketing Analytics Use in UK SME
}

\begin{tabular}{|r|l|}
\hline Journal: & Management Decision \\
\hline Manuscript ID & MD-07-2020-0945.R1 \\
\hline Manuscript Type: & Original Article \\
\hline Keywords: & $\begin{array}{l}\text { marketing analytics, configurations, small to medium-sized enterprises, } \\
\text { fsQCA, conditions }\end{array}$ \\
\hline
\end{tabular}

\section{SCHOLARONE \\ Manuscripts}




\section{ABSTRACT:}

While marketing analytics can be used to improve organizational decision-making and performance significantly, little research exists to examine how the configurations of multiple conditions affect marketing analytics use. This study draws on configuration theory to investigate marketing analytics use in small and medium-sized enterprises (SMEs).

This research employs fuzzy set qualitative comparative analysis using data collected from a survey of 187 managers in UK SMEs.

The key findings show that (1) configurations of multiple conditions provide alternative pathways to marketing analytics use; and (2) the configurations for small firms are different from those for medium-sized firms.

The research results are based on several key configurational factors and a single key-informant method to collect subjective data from UK SME managers.

The study helps SMEs to understand that marketing analytics use is influenced by the interaction of multiple conditions, that there are alternative pathways to marketing analytics use, and that SMEs should choose the configuration that fits best with their organizational contexts.

CUST_SOCIAL_IMPLICATIONS_(LIMIT_100_WORDS) :No data available.

The study contributes to the literature by addressing an important yet under-researched area, i.e. marketing analytics use in SMEs, applying a configurational approach to the research phenomenon. It highlights different pathways to marketing analytics use in SMEs. The findings provide empirical evidence on the possibility and implication of marketing analytics use being asymmetrical and different between small and medium-sized firms. 


\title{
Identifying the Configurational Conditions for Marketing Analytics Use in UK SMEs
}

\begin{abstract}
Purpose - While marketing analytics can be used to improve organizational decision-making and performance significantly, little research exists to examine how the configurations of multiple conditions affect marketing analytics use. This study draws on configuration theory to investigate marketing analytics use in small and medium-sized enterprises (SMEs).
\end{abstract}

Design/methodology/approach - This research employs fuzzy set qualitative comparative analysis using data collected from a survey of 187 managers in UK SMEs.

Findings - The key findings show that (1) configurations of multiple conditions provide alternative pathways to marketing analytics use; and (2) the configurations for small firms are different from those for medium-sized firms.

Research limitations/implications - The research results are based on several key configurational factors and a single key-informant method to collect subjective data from UK SME managers.

Practical implications - The study helps SMEs to understand that marketing analytics use is influenced by the interaction of multiple conditions, that there are alternative pathways to marketing analytics use, and that SMEs should choose the configuration that fits best with their organizational contexts.

Originality/value - The study contributes to the literature by addressing an important yet underresearched area, i.e. marketing analytics use in SMEs, applying a configurational approach to the research phenomenon. It highlights different pathways to marketing analytics use in SMEs. The findings provide empirical evidence on the possibility and implication of marketing analytics use being asymmetrical and different between small and medium-sized firms.

Keywords: marketing analytics, conditions, configurations, small to medium-sized enterprises, fsQCA

\section{Introduction}

Marketing analytics is a subset of business or big data analytics. It pertains to the collection, management, and analysis of data to extract useful insights to support marketing decisionmaking (Wedel and Kannan, 2016, Cao et al., 2019). Extant empirical research indicates that firms can use marketing analytics to improve marketing decision-making and firm competitiveness significantly, inter alia (e.g., Dremel et al., 2020, Cao et al., 2019). However, although firms are increasingly utilizing analytics for data-driven insights, and there has been a substantial amount of academic research into business analytics and its impact on 
organizations, understanding the conditions required for utilizing business analytics remains an important gap in the literature (Trieu, 2017, Mikalef et al., 2020) and deserves further investigation (Ghasemaghaei, 2019).

In particular, while there is indication that some SMEs (fewer than 250 employees) are benefiting from their analytics investment, there is a dearth of empirical research examining the use of business analytics and its effect on the performance of SMEs (e.g., Maroufkhani et al., 2020, Liu et al., 2020, Wang et al., 2018), despite the fact that SMEs are the backbone of national economies such as the UK, where SMEs account for more than $99.7 \%$ of all enterprises and employ 54\% of the workforce (Papadopoulos et al., 2020).

Hence, this research aims to address this gap and advance our understanding of marketing analytics use in SMEs by examining two research questions: What configurations of multiple conditions are likely to lead to marketing analytics use? and Do configurations of multiple conditions that lead to marketing analytics use differ between small and medium-sized firms?

This study addresses these two questions using a research design that is conceptually underpinned by configuration theory (Woodside, 2013, Fiss, 2011) and methodologically based on fuzzy-set qualitative comparative analysis (fsQCA) (Ragin and Davey, 2016). Most studies examining the factors that affect analytics use have employed conventional statistical methods to test causality, but Woodside (2013) argues that these methods are often less proficient at handling multi-faceted interdependencies between variables because these methods are typically based upon linear and symmetric relationships between variables of interest. This research argues that an outcome of interest, that is, marketing analytic use, seldom has a single cause but is best explained through multi-causality conditions; and that causes are interdependent rather than operating in isolation. Thus, configurational approach is seen to 
offer the possibilities of understanding how the multiple conditions combine into configurations to lead to equifinal pathways to marketing analytics use.

Drawing on configuration theory and analytics studies that adopted configurational approach (e.g., Park et al., 2017, WangKung et al., 2019), this study develops and tests a research model linking the configurations of multiple conditions to marketing analytics use. Built on prior studies, the conditions included in this study are those that are seen to be important antecedents to analytics applications, including managerial perception (Kearns and Sabherwal, 2007), managerial support (Chen et al., 2015, Liang et al., 2007), data availability (Gupta and George, 2016), competitive pressure (Liang et al., 2007), and organizational readiness (Iacovou et al., 1995, Chen et al., 2015).

Accordingly, this paper adopts fsQCA to handle the complex interdependencies between variables (Fiss, 2007, Woodside, 2013). Additionally, to extend the idea that firm size impacts information system (IS) investment and adoption patterns (e.g. Gillon et al., 2014, Thong et al., 1996, Dong and Yang, 2020), this study argues that small (fewer than 50 employees) and medium-sized firms (50 to 249 employees) may each have distinctive configurations of causal conditions, thereby affecting their marketing analytics use.

This study thus contributes to the under-researched marketing analytics use in SMEs. By suggesting that marketing analytics use is affected by the configurations of multiple conditions, this study applies configuration theory with marketing analytics research to develop a better understanding of marketing analytics use in SMEs. Moreover, by showing that the configurations for small firms are different from those for medium-sized firms, this research challenges the traditional way of examining SMEs as one homogeneous group, and suggests that it might be more pertinent to investigate small and medium-sized firms as heterogeneous clusters to understand their adoption patterns of marketing analytics. 
This paper proceeds as follows: the next section provides a review of relevant literature and current research gaps, followed by theoretical considerations. Then, the research methodology is described, including research design, sampling and data collection, fsQCA, measurement of variables, followed by the data analysis and results. Finally, the paper presents the discussion and implications, and summarizes its theoretical contributions, managerial implications, limitations and future research, and conclusions.

\section{Literature review}

Marketing analytics refers to the collection, management, and analysis of data to extract useful insights to support marketing decision-making (Wedel and Kannan, 2016), while its "use" refers to the extent to which a firm is employing marketing analytics to support marketing decision making (Ariker et al., 2015, Cao et al., 2019, CMO-Survey, 2016). Although marketing analytics is seen to create business value, the actual use, however, is surprisingly limited (Wedel and Kannan, 2016, Ariker et al., 2015), and the various conditions needed for an organization to use analytics to create business value are yet to be fully examined (Trieu, 2017, Ghasemaghaei, 2019, Mikalef et al., 2020), especially in SMEs.

Many firms have recognized the manifest potential of business analytics and are investing in analytics applications, but there is evidence to suggest that most firms that have adopted analytics applications have difficulties in attaining the anticipated competitive advantage (Božič and Dimovski, 2019, WangKung et al., 2019, Benoit et al., 2020). At the same time, scholars still struggle to theorize the value realization of business analytics (Dremel et al., 2020, Günther et al., 2017, Mikalef et al., 2020). Arguably, SMEs tend to have greater difficulties in exploiting analytics because of the relative scarcity of their resources, lack of specialist expertise, and small business size (Gillon et al., 2014, Liu et al., 2020, Maroufkhani et al., 2020, Hansen and Bøgh, 2020). These adversities are further exacerbated by a dearth of 
empirical studies examining the analytics' effect on the performance of SMEs (e.g. Maroufkhani et al., 2020, Liu et al., 2020, Wang et al., 2018).

While prior studies suggest that business/marketing analytics use can be affected by various conditions such as top management advocacy and analytics culture (Wedel and Kannan, 2016, Cao et al., 2019), technical compatibility, expected benefits, competitive pressure, data availability (e.g. Gupta and George, 2016, Cao et al., 2019), or organizational readiness (Chen et al., 2015), these studies fail to consider the complex interdependencies between variables or the configurations of causal conditions (Woodside, 2013, Fiss, 2011). Several recent analytics studies suggest that investigation of how the configurations of causal conditions affect organizational performance is largely absent from the existing literature (e.g. WangKung et al., 2019, Park et al., 2017).

Literature review shows that the adoption of qualitative comparative analysis (QCA) has been growing rapidly, substituting traditional correlation methods to establish causal conditions related to a particular result (Roig-Tierno et al., 2017). One of the QCA approaches is fuzzy-set qualitative comparative analysis (fsQCA) (Ragin and Davey, 2016), which has gained increasing attention and application in recent years (e.g., Poorkavoos et al., 2016, Douglas et al., 2020). fsQCA is seen to be advantageous for understanding SMEs' organizational relationships and has been used to examine, for example, design sprint approaches and collaborations (Magistretti et al., 2020), network and knowledge variables and international performance (Hughes et al., 2019), IT and HRM capabilities for competitive performance (Uwizeyemungu et al., 2018), and inter-organizational knowledge transfer networks, organizations' internal capabilities, and different types of innovation (Poorkavoos et al., 2016). However, no prior research has investigated how the configurations of multiple conditions affect business/marketing analytics use in SMEs. 
Based on the literature review, the following gaps concerning marketing analytics use are identified and will be addressed in this study: First, although studies have established the link between the use of business analytics and improved firm performance such as innovation (e.g., Duan et al., 2020), decision making effectiveness (e.g., Cao et al., 2015), supply chain performance (e.g., Zhan and Tan, 2020), and competitive advantages (e.g., Cao et al., 2019, WangYeoh et al., 2019), the majority of these studies are based on large companies and their findings should not be applied to SMEs directly without further investigation, as SMEs are not smaller versions of larger firms (O'Regan et al., 2005). Aside from only a few studies (e.g., Ferraris et al., 2019, Maroufkhani et al., 2020, Hansen and Bøgh, 2020, Liu et al., 2020), business/marketing analytics use and its effect on the performance of SMEs are yet to be fully investigated (e.g., Maroufkhani et al., 2020, Liu et al., 2020, Wang et al., 2018). Second, although prior studies have used configurational approaches to understand organizational relationships in SMEs (e.g., Hughes et al., 2019, Uwizeyemungu et al., 2018, Poorkavoos et al., 2016, Magistretti et al., 2020), no research has investigated how the configurations of multiple conditions affect business/marketing analytics use in SMEs. Third, while prior studies suggest that firm size matters (e.g. de Haan et al., 2007, Haase and Franco, 2011) and tends to be associated with different patterns of IS investment and use (e.g. Gillon et al., 2014, Thong et al., 1996, Haase and Franco, 2011, Dong and Yang, 2020), almost all prior analytics studies have examined SMEs as one homogeneous group (e.g., Ferraris et al., 2019, Maroufkhani et al., 2020, Hansen and Bøgh, 2020, Liu et al., 2020). Thus, whether or not small and mediumsized firms differ in terms of marketing analytics use remains unexamined in empirical research.

\section{Theoretical considerations}

To address the research gaps and develop an understanding of how configurations of multiple conditions may influence marketing analytics use in SMEs, this study draws on prior studies 
to look at the following five conditions: managerial perception and support, competitive pressure, data availability, and organizational readiness.

First, managerial perception generally refers to the degree to which the top management team views IS as critical to an organization's success, which is the primary determinant of IS adoption (e.g., Liang et al., 2007, Oliveira et al., 2014, Heath and Babu, 2017). For example, Grandon and Pearson (2004) show that SME managers' perceived strategic value of ecommerce is positively associated with its adoption. Liang et al. (2007) demonstrate that a firm's top managers' positive perception of IS results in actual IS assimilation. Thus, in this research, managerial perception is defined as the extent to which the top management team recognizes the strategic value of marketing analytics, which is expected to lead to actual marketing analytics use.

Second, managerial support refers to the extent to which the top management team understands, appreciates, and promotes the use of marketing analytics (Cao et al., 2019), which is considered necessary to fully exploit the benefits of IS (e.g., Thong et al., 1996, Ragu-Nathan et al., 2004) and is shown to be associated with IS adoption in SMEs (Grandon and Pearson, 2004). Recently, some analytics studies demonstrate that managerial support is positively associated with big data analytics use (Chen et al., 2015).

Third, data availability refers to the extent of a firm's access to (big) data for analysis, data integration of multiple internal sources for easy access, and integration of external and internal data (Gupta and George, 2016). This is important as data has been described as the basis for informing decision-making and a new form of capital that offers a firm innovative ways to differentiate its products. It is anticipated that data is more likely to be available when the top management team perceives that data is a core strategic asset.

Fourth, perceived competitive pressure is understood in terms of the extent to which a firm's competitors, suppliers, and customers have employed IS, which may apply some 
coercive pressure on a firm to use similar IS (Liang et al., 2007, Cao et al., 2019). Prior studies have shown that competitive pressure influences IS adoption in SMEs. For example, Low et al. (2011) find the adoption of cloud computing is affected by competitors' adoption and trading partner pressure, while Chen et al. (2015) show that competitive pressure is associated with big data analytics use. Similarly, this study expects that when a firm's top management team sees that its competitors and other business partners have used marketing analytics for business value creation, the firm is highly likely to use marketing analytics.

Fifth, organizational readiness refers to the extent to which organizational resources are available for using IS (e.g., Iacovou et al., 1995) or big data analytics (Chen et al., 2015). Such resources may include financial capital and the level of sophistication of IS usage and management (Iacovou et al., 1995), technological resources (Grandon and Pearson, 2004), and analytics skills or capability (Chen et al., 2015). Chen et al. (2015) suggest that a firm's top management team will be more supportive when they believe that the firm has sufficient resources in place to promote big data analytics use. Thus, this study expects that sufficient organizational resources will be directed toward marketing analytics use when the top management team has a positive perception of the value of such implementation, based on their overall interpretation of the analytics situations they face.

Finally, prior studies suggest that firm size matters and tends to be associated with different patterns of IS investment and use (e.g. Gillon et al., 2014, Thong et al., 1996, Haase and Franco, 2011, Dong and Yang, 2020). SMEs, because of their small business size, generally lack resources and specialist expertise, thus tend to have difficulties exploiting analytics (Gillon et al., 2014, Liu et al., 2020, Maroufkhani et al., 2020, Hansen and Bøgh, 2020). Nevertheless, there is evidence in the literature to suggest that some SMEs have adopted business analytics to improve decision making and to gain competitive advantages (Ferraris et al., 2019, Dong and Yang, 2020, Liu et al., 2020). While SMEs are traditionally examined as 
one homogeneous group (e.g., Ferraris et al., 2019, Maroufkhani et al., 2020, Hansen and Bøgh, 2020, Dong and Yang, 2020, Liu et al., 2020), there is evidence to suggest that small and medium-sized firms are significantly different (e.g. de Haan et al., 2007) and have distinctive patterns of IS adoption (e.g., Reyes et al., 2016, Gillon et al., 2014, Thong et al., 1996, Haase and Franco, 2011). Accordingly, it is also possible that marketing analytics use and its related configurational conditions differ between small and medium-sized firms.

Based on the literature review and the theoretical considerations, the following two research propositions are proposed:

Proposition 1: Marketing analytics use is associated with the configurations of managerial support, organizational readiness, managerial perception, data availability, and competitive pressure.

Proposition 2: The configurations of multiple conditions that lead to marketing analytics use differ between small and medium-sized firms.

\section{Research method}

\section{Research design}

To address the research questions, this study employed fsQCA to investigate what configurations of multiple conditions are associated with marketing analytics use and if the configurations leading to marketing analytics use differ between small and medium-sized firms. A survey questionnaire was used to collect data from a sample of UK manufacturing SMEs. This sector was selected because there is evidence to suggest that UK manufacturers tend to adopt a variety of innovative technological and process-based solutions (Chae et al., 2014), that the most successful manufacturers take a comprehensive approach to digitalization where big data analytics plays a key role (PWC-UK, 2018), and that, based on an OECD report, about $30 \%$ of UK SMEs have adopted big data analytics (Bianchini and Michalkova, 2019). Generally, manufacturers can use business analytics to improve decision making and 
manufacturing quality (Dubey et al., 2019, Dutta and Bose, 2015) or to provide the basis for identifying and deploying agile manufacturing practices (Gunasekaran et al., 2018), among others. Thus, UK SMEs provide a suitable context to examine the relationship between configurations of multiple conditions and marketing analytics use.

\section{Fuzzy-set qualitative comparative analysis}

fsQCA was used to analyze configurations of multiple conditions. A configurational approach can be compared with the traditional regression-based methods. The latter typically focus on predicting levels of an outcome $\mathrm{Y}$ from levels of predictor $\mathrm{X}$, and assuming a symmetrical relationship between X and Y (Fiss, 2007, Woodside, 2013). However, regression-based methods may be insufficient for studying the complex interdependencies between variables, which could be better explained through a configurational approach (Fiss, 2007, Woodside, 2013).

Acording to Dess et al. (1993), "a configuration represents a number of specific and separate attributes which are meaningful collectively rather than individually" (p.775), which can be used in studies of organizations to "express complicated and interrelated relationships among many variables" (p.776). Meyer et al. (1993) assert that configurational inquiry is holistic, that is, an outcome emerges from the interaction of the variables as a whole, and the variables take their meaning from the whole and cannot be understood in isolation. Thus, a configurational approach suggests that an outcome of interest seldom has a single cause but is best explained through multi-causality considerations; and that causes are interdependent rather than operating in isolation. Fundamentally, configuration theory accomodates the principle of equifinality-that is, "a system can reach the same final state from different initial conditions and by a variety of different paths of development" (Katz and Kahn, 1978, p.30). Configuration theory also assumes causal asymmetry (Ragin, 2008), which asserts that the causes leading to 
the presence of an outcome of interest may be quite different from those leading to the absence of the outcome (Fiss, 2007, Fiss, 2011).

Qualitative comparative analysis (QCA) has two most common variants: fsQCA and crisp-set QCA (csQCA). csQCA uses categorical conditions based on a dichotomy, assigning the values 1 - full membership, or 0 - full non-membership, to each condition. This approach has limitations in practice as it is not possible to assign values to gradual conditions occurring in the social reality such as quality, satisfaction, etc. In contrast, fsQCA developed by Ragin (2000) and Ragin (2008) is based on the concept of fuzzy set, that is, a class of objects with a continuum of grades of membership (Zadeh, 1965). By using fuzzy sets, fsQCA involves a more accurate and rigorous consistency assessment than csQCA, which can only analyze binary membership (Xie and Wang, 2020). Therefore, fsQCA has attracted the most attention in terms of amount of research with the number of studies using fuzzy sets growing exponentially (Roig-Tierno et al., 2017).

\section{Sampling and data collection}

The FAME database (Financial Analysis Made Easy) was utilized to obtain a convenience sample of 32,118 senior and middle managers from UK SMEs. A survey questionnaire was developed and then distributed to managers electronically through Qualtrics, an online survey tool. Four rounds (the survey plus three follow-ups), one-week apart, of emails with the questionnaire survey were conducted. Of all sent emails, 187 usable responses were received, 104 responses from small firms and 83 responses from medium-sized firms. For fsQCA analysis, 187 responses are deemed suitable because QCA techniques including fsQCA combine quantitative and qualitative methodologies (Ragin, 2000, Ragin, 2008). Although QCA focused on small samples originally, its further development has allowed its application to broader contexts (Roig-Tierno et al., 2017). 
Since all data were gathered from a single key respondent within each firm, a potential for common method bias exists (Podsakoff et al., 2012). To address this issue, several steps were undertaken to minimize common method bias, following the suggestions made by Tehseen et al. (2017). First, three procedural remedies were used to reduce common method bias by (a) defining scale items clearly and keeping questions simple and specific, (b) labelling every point on the response scale to reduce item ambiguity (Krosnick, 1999), and (c) using positively and negatively worded measures to control for acquiescence and disacquiescence biases (Podsakoff et al., 2012). Second, statistical analyses were employed to test common method bias. Harman single-factor test was conducted and showed that the first factor accounted for $13.81 \%$ of the total variance, suggesting that common method bias was not a serious concern. Additionally, the partial correlation procedure (Lindell and Whitney, 2001) was performed using respondent's tenure as a marker variable, which is theoretically unrelated to marketing analytics use. The result indicated that there were no significant changes in any of the study correlations, which again suggested that there was no serious issue of common method bias (Lindell and Whitney, 2001).

Non-response bias was also tested to ensure that the sample was representative of the panel population. As non-respondents are found to resemble late respondents (Armstrong and Overton, 1977), the differences between early respondents and late respondents were examined using a t-test. The analysis showed that both groups did not differ significantly in their responses, indicating no systematic differences between the two groups. Furthermore, based on the known value for the population approach (Armstrong and Overton, 1977), a nonparametric chi-square test was conducted to compare the distribution of the company size of the respondents with that of the complete sampling frame generated from FAME. The test result found that there were no significant differences between respondents and nonrespondents. 


\section{Measurement of variables}

In line with previous analytics research, the outcome variable - marketing analytics use - was measured using Likert-type scales (ranging from $1=$ no use to $7=$ very heavy use) by adopting 13 items reported by CMO-Surveys (2016): using analytics in customer insight, customer acquisition, customer retention, customer segmentation, new product or service development, product or service strategy, promotion strategy, pricing strategy, marketing mix, branding, digital marketing, social media, and multichannel marketing.

The five conditions - managerial perception and support, competitive pressure, data availability, and organizational readiness - were also measured using a seven-point Likert scale (anchored at $1=$ strongly disagree to $7=$ strongly agree). Data availability was measured using three items adapted from Gupta and George (2016). Managerial perception was measured using four items adapted from Kearns and Sabherwal (2007). Managerial support was measured based on three items adapted from prior studies (Chen et al., 2015, Liang et al., 2007). Competitive pressure was measured using three items adapted from Liang et al. (2007). Finally, organizational readiness was measured using four items adapted from prior studies (Iacovou et al., 1995, Chen et al., 2015).

The construct validity of the measurement included in the questionnaire was assessed by considering the internal consistency (composite reliability), indictor reliability, convergent validity and discriminant validity (Hair et al., 2014). As is shown in Table I, the values of composite reliability (CR) and average variance extracted (AVE) for the constructs are all above Hair's recommended thresholds of 0.7 and 0.5 , respectively. These results show that adequate convergent validity and discriminant validity were obtained for the measurement scales.

(Insert Table I here)

\section{Analysis and results}




\section{Calibration}

The program fsQCA 3.0 (Ragin and Davey, 2016) was used for data calibration. Based on the calibration procedure suggested by Ragin (2008), variables were transformed into fuzzy sets with values ranging from 0 - no set membership to 1 - full set membership. Since a sevenpoint Likert scale was used to quantify constructs, in line with the guideline of calibration for survey measurement (Fiss, 2011), this study defined a value of 6 as the full membership anchor, 2 as the anchor for full non-membership, and 4 as the crossover point.

\section{Analysis of sufficient conditions}

After data calibration was completed, data were analyzed to identify which combinations of conditions are sufficient to obtain an outcome. In fsQCA, a causal condition is defined as sufficient if it can produce a certain outcome by itself (Fiss, 2011). The analysis started with the construction of a truth table, listing all logically possible configurations of the conditions for an outcome. As five conditions were considered in this study, the truth table consisted of $2^{5}=32$ different configurations. To reduce the truth table to meaningful configurations, a frequency threshold of five observations was chosen to exclude less important configurations.

In order to define which configurations were sufficient for achieving the outcome, this study set consistency for solutions at $\geq 0.80$, which is above the minimum threshold of 0.75 recommended by Ragin (2008) and Woodside (2013). The fsQCA software produces complex, intermediate and parsimonious solutions. In general, there can be a large number of complex solutions, often including impractical configurations. For this reason, they are usually simplified further into parsimonious and intermediate solutions that allow core or peripheral conditions to be differentiated, with "core elements as those causal conditions for which the evidence indicates a strong causal relationship with the outcome of interest and peripheral elements as those for which the evidence for a causal relationship with the outcome is weaker" (Fiss, 2011, p.394). In fsQCA, core conditions are those that are part of both parsimonious and 
intermediate solutions, peripheral conditions are those that only appear in intermediate solutions.

Table II summarizes the intermediate solutions with the presence of marketing analytics use as outcomes. Solid circles “•” represent the presence of causal conditions and empty circles “○" represent the absence or negation of causal conditions. The blank cells represent "doesn’t matter" conditions. Furthermore, large circles indicate core conditions, and small circles indicate peripheral conditions (Fiss, 2011).

\section{(Insert Table II here)}

To conclude whether or not the configurations are informative, two measures are available: consistency and coverage. First, consistency measures the extent to which a configuration is a sufficient condition for the outcome (Ragin, 2008). As all of the consistency scores exceeded the cut-off value ( $\geq 0.75$ ), all configurations were considered as sufficient for the outcome (Fiss, 2011, Fiss, 2007). Second, the coverage scores assess the proportion of cases that follow a particular path and thus capture the empirical importance of an identified configuration. The raw coverage quantifies the proportion of outcome cases explained by a given configuration, ranging from 0.47 to 0.62 . The higher the raw coverage, the larger the proportion of marketing analytics use can be explained by the given configuration. Unique coverage measures the proportion of outcome cases that are uniquely covered by a given path (Ragin, 2008), which should be larger than zero; otherwise the configuration does not contribute to the explanation of the outcome. Table II indicates that this requirement is fulfilled.

Finally, the overall solution was seen to be informative as both the overall solution coverage and overall solution consistency were satisfactory. Table II indicates that the overall solution coverage is 0.51 for small firms and 0.67 for medium-sized firms, which measures to what extent the cases that indicate the presence of marketing analytics use are covered by at least one of the configurations from the solution set and thus indicates the joint importance of 
all configurations accounting for marketing analytics use. The overall solution consistency measures the degree to which all configurations together reliably result in marketing analytics use, which is 0.81 for both small and medium-sized firms and satisfactorily exceeds the threshold of 0.75 (Ragin, 2008, Woodside, 2013).

\section{Configurations for the presence of marketing analytics use}

Overall, the findings in Table II show that the configurations differ by firm size. For small firms, there is only one configuration for marketing analytics use. However, two configurations exist for marketing analytics use in medium-sized firms, which are considered as equally important because each forms a different but sufficient path to marketing analytics use. Nevertheless, the two pathways obviously differ in empirical strength: the raw coverage of M2 is higher than that of M1; thus, the former contains more cases than the latter.

The results also indicate the presence of different patterns of core and peripheral conditions of marketing analytics use. Specifically, for small firms, the combination of data availability and organizational readiness is core and all other conditions are peripheral. For medium-sized firms, managerial support is core while the other four conditions are peripheral.

\section{Configurations for the absence of marketing analytics use}

As mentioned earlier, fsQCA accounts for the possibility of causal asymmetry, that is, configurations leading to an outcome might be quite different from those leading to the absence of the outcome (Fiss, 2007, Woodside, 2013). In other words, improving certain conditions within a configuration can lead to an outcome of interest; however, a reduction of these conditions may not be associated with lower degrees of the outcome. To test this, another set of fsQCA analyses was conducted in which the absence of marketing analytics use represents the outcome for both small and medium-sized firms. Different patterns of solutions for the absence of marketing analytics use were found for SMEs (Table III). 
(Insert Table III here)

Compared to the only configuration leading to marketing analytics use in small firms (see Table II), there are four configurations for the absence of marketing analytics use in small firms. For medium-sized firms, three different patterns of solutions for the absence of marketing analytics use are found. Across SMEs and all absence configurations, either the lack of managerial support or the lack of organizational readiness is a core condition. Comparing absence to presence configurations of marketing analytics use, the analysis indicates clearly that asymmetric causality exists. Different sets of core and peripheral conditions are also observable for the absence or presence of marketing analytics use.

\section{Discussion and implications}

\section{Discussion}

Whilst research suggests that understanding the conditions required for utilizing business analytics remains an important gap in the literature (Trieu, 2017, Ghasemaghaei, 2019, Mikalef et al., 2020), understanding how configurations of multiple conditions affecting business/marketing analytics use has rarely been investigated (e.g., Maroufkhani et al., 2020, Liu et al., 2020, Wang et al., 2018). To contribute to filling this gap, this study, drawing on configuration theory (Fiss, 2011, Fiss, 2007), examined (a) the configurations of conditions that lead to marketing analytics use, and (b) the configuration similarities and differences between small and medium-sized firms.

With respect to Proposition 1 that postulates that the configurations of multiple conditions are associated with marketing analytics use, the results of this study, summarized in Table II, suggest that for small firms there is only one sufficient configuration leading to marketing analytics use, which is shaped collectively by managerial perception and support, competitive pressure, data availability, and organizational readiness. While all five conditions work together holistically, the combination of data availability and organizational readiness is 
a core condition and the other three conditions are peripheral. For medium sized firms, two alternative configurations leading to marketing analytics use are found, which is in line with the concept of equifinality. A closer look reveals that configuration M2, with a raw coverage of 0.62 , is linked to marketing analytics use more often than configuration M1, with a raw coverage of 0.47 . While the two configurations share a common core condition - managerial support - each configuration has a set of different conditions. This supports the idea that how conditions combine is key to deciding whether certain conditions are sufficient for utilizing marketing analytics or not. Additionally, the core conditions for both small and medium-sized firms found in this study appear to be consistent with prior analytics studies about them being important precursors to a firm's analytics use (e.g., Gupta and George, 2016, Cao et al., 2019); nonetheless, the current findings are based on an entirely different perspective which is that conditions are understood as a "core" conditions of configurations rather than an "individual" one. Thus, Proposition 1 is supported, providing fresh insight into understanding the conditions required for SMEs to utilize marketing analytics. One implication of the configurations identified in this study is that SMEs that wish to utilize marketing analytics need to ensure that all key conditions for a configuration are to be met holistically. Another is that while multiple causal conditions collectively define a sufficient configuration, some conditions can be regarded as essential while others can be of less importance.

With regard to Proposition 2 that posits that small and medium-sized firms differ in terms of the configurations leading to marketing analytics use, this study found several differences. Firstly, small firms have only one configuration shaped by all five conditions while medium-sized firms have two different pathways to marketing analytics use. Secondly, for medium-sized firms, managerial support is a core condition for the two configurations, which is consistent with prior research using regression-based methods (Chen et al., 2015, Thong et $a l .$, 1996). However, for small firms, the combination of data availability and organizational 
readiness is a core condition; and contrary to expectations, managerial support is not. At first sight, this may seem to be puzzling, but it actually makes much sense. It is possible that medium-sized firms have a higher level of resource readiness than small firms, so managerial support becomes a core condition for utilizing marketing analytics. Quite the reverse, prior research suggests that small firms lack the resources needed for IS implementation in general (Oliveira et al., 2014) and the analytics resources in particular (Gillon et al., 2014). Consequently, the presence of the combination of data availability and organizational readiness is more important than that of managerial support for small firms as without the former, the latter itself will not result in a firm's use of marketing analytics. Thus, Proposition 2 is supported.

Additionally, the configuration similarities and differences between small and mediumsized firms can be further demonstrated by the configurations for the absence of marketing analytics use, which account for possible causal asymmetry. Table III indicates that the similarity is that all the configurations for the absence of marketing analytics use have the same core condition - the lack of either managerial support or organizational readiness. On the other hand, small firms have four configurations for the absence, which is in stark contrast with the only configuration for the presence, of marketing analytics use. Thus, it is clear that the configuration for the presence is not just the reverse of the configurations for the absence. In contrast, medium-sized firms have three configurations for the absence. These outcomes seem to suggest that small firms are more likely to be absent from utilizing marketing analytics than medium-sized firms. Most notably, a careful analysis of causal asymmetry shows that configurations $\mathrm{Sa} 4$ and $\mathrm{Ma} 2$ indicate that even when competitive pressure, managerial perception, and managerial support are all present; they cannot counteract the absence of organizational readiness. This confirms the idea that lacking necessary resources is a significant issue for IS adoption in SMEs (e.g., Thong et al., 1996, Gillon et al., 2014, Liu et al., 2020, 
Maroufkhani et al., 2020, Hansen and Bøgh, 2020). It is clear from the study's findings that the relationship between marketing analytics use and the core conditions is asymmetrical rather than symmetrical.

Taken together, this study's findings provide empirical evidence that multiple configurations that lead to the presence or the absence of marketing analytics use exist and these differ by firm size. Moreover, none of the conditions considered in this study are selfsufficient for marketing analytics, which is substantially different from the findings of prior studies using regression-based methods.

\section{Theoretical contributions}

This study makes important theoretical contributions. First, in the process of developing an understanding of the relationship between the configurations of multiple conditions and marketing analytics use in SMEs, the present study extends the marketing analytics literature by suggesting and applying a configurational approach to conceptualizing and addressing the under-researched marketing analytics use in SMEs (e.g., Maroufkhani et al., 2020, Liu et al., 2020, Wang et al., 2018). Although a few studies have employed configurational approaches to examine organizational relations in SMEs (e.g., Hughes et al., 2019, Uwizeyemungu et al., 2018, Poorkavoos et al., 2016, Magistretti et al., 2020), this study is among the first to examine marketing analytics use affected by the multitude of conditions based on configuration theory. The findings strongly suggest that marketing analytics use has no single cause but is best explained through combinations of conditions holistically.

Second, this study extends the scope of analytics research by conceptualizing and empirically demonstrating that the conditions leading to analytics applications can be asymmetrical, thus more complex than assumed by most analytics studies based on regressionbased methods (e.g., Gupta and George, 2016). An important implication of this study is the need to unearth the assumptions that underlie analytics studies and to consider the possibility 
and implication of analytics phenomena being asymmetrical, which could lead to the development of a more in-depth understanding of analytics phenomena.

Third, whilst SMEs are traditionally examined as one homogeneous group (e.g., Ferraris et al., 2019, Maroufkhani et al., 2020, Hansen and Bøgh, 2020, Dong and Yang, 2020, Liu et al., 2020), this study provides additional empirical evidence to support the idea that small and medium-sized firms could have distinctive patterns of IS adoption (e.g., Reyes et al., 2016, Gillon et al., 2014, Thong et al., 1996, Haase and Franco, 2011). The implications of this finding are twofold. First, as shown in this study that small and medium-sized firms have different paths to marketing analytics use, so examining SMEs as one homogeneous group may not be able to distinguish the differences and generate the most suitable solutions. Second, instead of, as traditionally, assuming SMEs to be one homogeneous group, it seems appropriate to consider the possibility of small and medium-sized firms being heterogeneous in certain situations, which could lead to a more comprehensive understanding of how small and medium-sized firms utilize marketing analytics or other ISs.

\section{Managerial implications}

This study also offers valuable managerial implications for analytics practice in SMEs. First, SMEs should be aware of the fact that marketing analytics use is influenced by multiple conditions. These conditions are interrelated and interacting, and will combine into configurations that will collectively influence marketing analytics use. Thus, SMEs are recommended to take a more holistic view to consider the configurations of multiple conditions and their effects on marketing analytics use; such an approach is more likely to help SMEs mitigate the difficulties in attaining the anticipated benefits to be gained from analytics applications.

Second, medium-sized firms should ensure that they have their senior managers' support, as the latter is a core condition for marketing analytics use. Additionally, a medium- 
sized firm should select from the alternative pathways to marketing analytics use so the selected approach can best fit with its organizational context. However, for small firms, it is recommended that they should ensure that all conditions are satisfied as the only configuration for marketing analytics use is shaped simultaneously by managerial perception and support, competitive pressure, data availability, and organizational readiness. More importantly, small firms must ensure that they have access to data for analysis and various organizational resources for using marketing analytics, since the combination of data availability and organizational readiness is the core condition for them to use and benefit from their analytics investments.

\section{Limitations and future research}

There are several limitations in this study which offer opportunities for future research. First, any configurational study is limited in the number of factors it can include (Fiss, 2011); one potential avenue for future research is to extend this study by adding additional conditions or a different set of conditions, thereby either testing the usefulness of the configurations identified in this study or identifying new ones.

Second, the current sample is restricted to SMEs in the UK. Thus, the findings should be understood in this context and their applicability to SMEs in other countries needs to be tested. Future research could be conducted to investigate whether or not the configurations identified in this study are likely to differ in multi-country contexts.

Third, future studies can also adopt qualitative methods, e.g., case studies, to develop in-depth understanding of how and why different conditions and their combinations affect business/marketing analytics use.

Fourth, this study uses fsQCA due to its unique advantages. Future research could use fsQCA to complement statistical methods, which could potentially lead to a more comprehensive analysis. Finally, this study employs a single key-informant method to collect 
subjective data from each firm; future research could collect objective data if it is available and/or use multiple informants from each firm to limit potential subjective bias.

\section{Conclusions}

Although SMEs are the backbone of national economies and business analytics can be used to improve organizational decision-making and performance significantly, understanding the conditions required for firms to effectively use business analytics remains an important gap in the literature. In particular, there is a dearth of empirical research examining how configurations of multiple conditions affect business analytics use. To help SMEs better realize the manifest potentials of using marketing analytics, this study is among the first to draw on configuration theory to examine how multiple configurations of conditions lead to marketing analytics use in SMEs by employing fsQCA.

The empirical evidence led to the conclusion that the presence or the absence of marketing analytics use in SMEs is ultimately influenced by the configuration of various conditions and that analytics phenomena could be asymmetrical. Thus, an important implication for analytics research is the need to challenge the well-accepted symmetrical assumptions about analytics phenomena and to consider employing a configurational approach to developing an alternative and more holistic understanding of analytics phenomena. Additionally, the empirical finding demonstrated that firm size matters as small and mediumsized firms each have distinctive patterns of marketing analytics use. Thus, it seems pertinent to examine SMEs as heterogeneous rather than homogeneous clusters.

SMEs that wish to invest in marketing analytics and want to maximize its potential effect on marketing decision making and organizational performance should pay particular attention to the need for understanding the configurations of multiple conditions required for using marketing analytics, being aware of the alternative pathways to marketing analytics use, and selecting the configuration that best fits their own organizational contexts. 


\section{References}

Ariker, M., Diaz, A., Moorman, C. and Westover, M. (2015), Quantifying the Impact of Marketing Analytics. Harvard Business Review Digital Articles, pp.2-5.

Armstrong, J. S. and Overton, T. S. (1977), Estimating Nonresponse Bias in Mail Surveys. Journal of Marketing Research (JMR), Vol.14 No.3, pp.396-402.

Benoit, D. F., Lessmann, S. and Verbeke, W. (2020), On realising the utopian potential of big data analytics for maximising return on marketing investments. Journal of Marketing Management, Vol.36 No.3/4, pp.233-247.

Bianchini, M. and Michalkova, V. (2019), Data Analytics in SMEs: Trends and Policies. (Accessed).

Božič, K. and Dimovski, V. (2019), Business intelligence and analytics use, innovation ambidexterity, and firm performance: A dynamic capabilities perspective. The Journal of Strategic Information Systems, Vol.28 No.4, pp.101578.

Cao, G., Duan, Y. and El Banna, A. (2019), A dynamic capability view of marketing analytics: Evidence from UK firms. Industrial Marketing Management, Vol.76, pp.72-83.

Cao, G., Duan, Y. and Li, G. (2015), Linking Business Analytics to Decision Making Effectiveness: A Path Model Analysis. IEEE Transactions on Engineering Management, Vol.62 No.3, pp.384-395.

Chae, B., Olson, D. and Sheu, C. (2014), The impact of supply chain analytics on operational performance: a resource-based view. International Journal of Production Research, Vol.52 No.16, pp.4695-4710.

Chen, D., Preston, D. S. and Swink, M. (2015), How the Use of Big Data Analytics Affects Value Creation in Supply Chain Management. Journal of Management Information Systems, Vol.32 No.4, pp.4-39.

CMO-Survey. (2016), Highlights and Insights Report [Online]. Available: https://cmosurvey.org/wpcontent/uploads/sites/11/2016/08/The CMO Survey-Highlights and Insights-Aug-2016.pdf (Accessed April 16 2020).

de Haan, J., Kisperska-Moroń, D. and Placzek, E. (2007), Logistics management and firm size; a survey among Polish small and medium enterprises. International Journal of Production Economics, Vol.108 No.1-2, pp.119-126.

Dess, G. G., Newport, S. and Rasheed, A. M. (1993), Configuration research in strategic management: Key issues and suggestions. Journal of Management, Vol.19 No.4, pp.775-795.

Dong, J. Q. and Yang, C.-H. (2020), Business value of big data analytics: A systems-theoretic approach and empirical test. Information \& Management, Vol.57 No.1, pp.103124.

Douglas, E. J., Shepherd, D. A. and Prentice, C. (2020), Using fuzzy-set qualitative comparative analysis for a finer-grained understanding of entrepreneurship. Journal of Business Venturing, Vol.35 No.1, pp.105970.

Dremel, C., Herterich, M. M., Wulf, J. and vom Brocke, J. (2020), Actualizing big data analytics affordances: A revelatory case study. Information \& Management, Vol.57 No.1, pp.103121.

Duan, Y., Cao, G. and Edwards, J. S. (2020), Understanding the impact of business analytics on innovation. European Journal of Operational Research, Vol.281 No.3, pp.673-686.

Dubey, R., Gunasekaran, A., Childe, S. J., Blome, C. and Papadopoulos, T. (2019), Big data and predictive analytics and manufacturing performance: integrating institutional theory, resource based view and big data culture. British Journal of Management, Vol.30 No.2, pp.341-361.

Dutta, D. and Bose, I. (2015), Managing a Big Data project: The case of Ramco Cements Limited. International Journal of Production Economics, Vol.165, pp.293-306.

Ferraris, A., Mazzoleni, A., Devalle, A. and Couturier, J. (2019), Big data analytics capabilities and knowledge management: impact on firm performance. Management Decision, Vol.57 No.8, pp.1923-1936.

Fiss, P. C. (2007), A set-theoretic approach to organizational configurations. Academy of management review, Vol.32 No.4, pp.1180-1198.

Fiss, P. C. (2011), Building better casual theories: A fuzzy set approach to typologies in organizational research. Academy of Management Journal, Vol.54 No.2, pp.393-420.

Ghasemaghaei, M. (2019), Does data analytics use improve firm decision making quality? The role of knowledge sharing and data analytics competency. Decision Support Systems, Vol.120, pp.14-24. 
Gillon, K., Aral, S., Ching-Yung, L., Mithas, S. and Zozulia, M. (2014), Business analytics: radical shift or incremental change? Communications of the Association for Information Systems, Vol.34 No.1, pp.287-296.

Grandon, E. E. and Pearson, J. M. (2004), Electronic commerce adoption: an empirical study of small and medium US businesses. Information \& management, Vol.42 No.1, pp.197-216.

Gunasekaran, A., Yusuf, Y. Y., Adeleye, E. O. and Papadopoulos, T. (2018), Agile manufacturing practices: the role of big data and business analytics with multiple case studies. International Journal of Production Research, Vol.56 No.1-2, pp.385-397.

Günther, W. A., Mehrizi, M. H. R., Huysman, M. and Feldberg, F. (2017), Debating big data: A literature review on realizing value from big data. The Journal of Strategic Information Systems, Vol.26 No.3, pp.191-209.

Gupta, M. and George, J. F. (2016), Toward the development of a big data analytics capability. Information \& Management, Vol.53 No.6, pp.1049-1064.

Haase, H. and Franco, M. (2011), Information sources for environmental scanning: do industry and firm size matter? Management Decision, Vol.49 No.10, pp.1642-1657.

Hair, J. F., Hult, G., Ringle, C. and Sarstedt, M. (2014), A Primer on Partial Least Squares Structural Equation Modeling (PLS-SEM), Sage.

Hansen, E. B. and Bøgh, S. (2020), Artificial intelligence and internet of things in small and mediumsized enterprises: A survey. Journal of Manufacturing Systems.

Heath, D. and Babu, R. (2017), Theorizing managerial perceptions, enabling IT, and the social inclusion of workers with disabilities. Information \& Organization, Vol.27 No.4, pp.211-225.

Hughes, M., Cesinger, B., Cheng, C.-F., Schuessler, F. and Kraus, S. (2019), A configurational analysis of network and knowledge variables explaining Born Globals' and late internationalizing SMEs' international performance. Industrial Marketing Management, Vol.80, pp.172-187.

Iacovou, C. L., Benbasat, I. and Dexter, A. S. (1995), Electronic data interchange and small organizations: Adoption and impact of technology. MIS Quarterly, Vol.19 No.4, pp.465-485.

Katz, D. and Kahn, R. L. (1978), The social psychology of organizations, Wiley New York.

Kearns, G. S. and Sabherwal, R. (2007), Antecedents and Consequences of Information Systems Planning Integration. IEEE Transactions on Engineering Management, Vol.54 No.4, pp.628-643.

Krosnick, J. A. (1999), Survey research. Annual Review of Psychology, Vol.50 No.1, pp.537-567.

Liang, H., Saraf, N., Hu, Q. and Xue, Y. (2007), Assimilation of enterprise systems: the effect of institutional pressures and the mediating role of top management. MIS quarterly, pp.59-87.

Lindell, M. K. and Whitney, D. J. (2001), Accounting for common method variance in cross-sectional research designs. Journal of applied psychology, Vol.86 No.1, pp.114-121.

Liu, Y., Soroka, A., Han, L., Jian, J. and Tang, M. (2020), Cloud-based big data analytics for customer insight-driven design innovation in SMEs. International Journal of Information Management, Vol.51, pp.102034.

Low, C., Chen, Y. and Wu, M. (2011), Understanding the determinants of cloud computing adoption. Industrial management \& data systems, Vol.111 No.7, pp.1006-1023.

Magistretti, S., Dell'Era, C. and Doppio, N. (2020), Design sprint for SMEs: an organizational taxonomy based on configuration theory. Management Decision, Vol.58 No.9, pp.1803-1817.

Maroufkhani, P., Tseng, M.-L., Iranmanesh, M., Ismail, W. K. W. and Khalid, H. (2020), Big data analytics adoption: Determinants and performances among small to medium-sized enterprises. International Journal of Information Management, Vol.54, pp.102190.

Meyer, A. D., Tsui, A. S. and Hinings, C. R. (1993), Configurational approaches to organizational analysis. Academy of Management journal, Vol.36 No.6, pp.1175-1195.

Mikalef, P., Krogstie, J., Pappas, I. O. and Pavlou, P. (2020), Exploring the relationship between big data analytics capability and competitive performance: The mediating roles of dynamic and operational capabilities. Information \& Management, Vol.57 No.2, pp.103169.

O'Regan, N., Sims, M. and Ghobadian, A. (2005), High performance: ownership and decision-making in SMEs. Management Decision, Vol.43 No.3, pp.382-396.

Oliveira, T., Thomas, M. and Espadanal, M. (2014), Assessing the determinants of cloud computing adoption: An analysis of the manufacturing and services sectors. Information \& Management, Vol.51 No.5, pp.497-510. 
Papadopoulos, G., Rikama, S., Alajääskö, P. and Salah-Eddine, Z. (2020), Statistics on small and medium-sized enterprises [Online]. Available: https://ec.europa.eu/eurostat/statisticsexplained/index.php?title=Statistics on small and medium-sized enterprises (Accessed January 5 2021).

Park, Y., El Sawy, O. A. and Fiss, P. C. (2017), The Role of Business Intelligence and Communication Technologies in Organizational Agility: A Configurational Approach. Journal of the Association for Information Systems, Vol.18 No.9, pp.648-686.

Podsakoff, P. M., MacKenzie, S. B. and Podsakoff, N. P. (2012), Sources of Method Bias in Social Science Research and Recommendations on How to Control It. Annual Review of Psychology, Vol.63 No.1, pp.539-569.

Poorkavoos, M., Duan, Y., Edwards, J. S. and Ramanathan, R. (2016), Identifying the configurational paths to innovation in SMEs: A fuzzy-set qualitative comparative analysis. Journal of Business Research, Vol.69 No.12, pp.5843-5854.

PWC-UK. (2018), Annual Manufacturing Report 2018. Available:vailable: https://www.pwc.co.uk/industries/assets/annual-manufacturing-report-2018.pdf (Accessed January 12, 2021).

Ragin, C. C. (2000), Fuzzy-set social science, University of Chicago Press.

Ragin, C. C. (2008), Redesigning social inquiry: Fuzzy sets and beyond, University of Chicago Press.

Ragin, C. C. and Davey, S. (2016), Fuzzy-Set/Qualitative Comparative Analysis 3.0. , Irvine, California, Department of Sociology, University of California.

Ragu-Nathan, B. S., Apigian, C. H., Ragu-Nathan, T. S. and Tu, Q. (2004), A path analytic study of the effect of top management support for information systems performance. Omega, Vol.32 No.6, pp.459-471.

Reyes, P. M., Li, S. and Visich, J. K. (2016), Determinants of RFID adoption stage and perceived benefits. European Journal of Operational Research, Vol.254 No.3, pp.801-812.

Roig-Tierno, N., Gonzalez-Cruz, T. F. and Llopis-Martinez, J. (2017), An overview of qualitative comparative analysis: A bibliometric analysis. Journal of Innovation \& Knowledge, Vol.2 No.1, pp.15-23.

Tehseen, S., Ramayah, T. and Sajilan, S. (2017), Testing and controlling for common method variance: A review of available methods. Journal of Management Sciences, Vol.4 No.2, pp.142-168.

Thong, J. Y. L., Chee-Sing, Y. and Raman, K. S. (1996), Top Management Support, External Expertise and Information Systems Implementation in Small Businesses. Information Systems Research, Vol.7 No.2, pp.248-267.

Trieu, V.-H. (2017), Getting value from Business Intelligence systems: A review and research agenda. Decision Support Systems, Vol.93, pp.111-124.

Uwizeyemungu, S., Raymond, L., Poba-Nzaou, P. and St-Pierre, J. (2018), The complementarity of IT and HRM capabilities for competitive performance: a configurational analysis of manufacturing and industrial service SMEs. Enterprise Information Systems, Vol.12 No.10, pp.1336-1358.

Wang, S., Yeoh, W., Richards, G., Wong, S. F. and Chang, Y. (2019), Harnessing business analytics value through organizational absorptive capacity. Information \& Management, Vol.56 No.7, pp.103152.

Wang, Y., Kung, L., Gupta, S. and Ozdemir, S. (2019), Leveraging big data analytics to improve quality of care in healthcare organizations: A configurational perspective. British Journal of Management, Vol.30 No.2, pp.362-388.

Wang, Y., Kung, L., Wang, W. Y. C. and Cegielski, C. G. (2018), An integrated big data analyticsenabled transformation model: Application to health care. Information \& Management, Vol.55 No.1, pp.64-79.

Wedel, M. and Kannan, P. K. (2016), Marketing Analytics for Data-Rich Environments. Journal of Marketing, Vol.80 No.6, pp.97-121.

Woodside, A. G. (2013), Moving beyond multiple regression analysis to algorithms: Calling for adoption of a paradigm shift from symmetric to asymmetric thinking in data analysis and crafting theory. Journal of Business Research, Vol.66, pp.463-472.

Xie, X. and Wang, H. (2020), How can open innovation ecosystem modes push product innovation forward? An fsQCA analysis. Journal of Business Research, Vol.108, pp.29-41.

Zadeh, L. A. (1965), Fuzzy sets. Information and Control, Vol.8 No.3, pp.338-353. 
Zhan, Y. and Tan, K. H. (2020), An analytic infrastructure for harvesting big data to enhance supply chain performance. European Journal of Operational Research, Vol.281 No.3, pp.559-574. 
Table I. Measurement Items and Descriptive Statistics

\begin{tabular}{|c|c|c|c|c|}
\hline Constructs & Indicators $(1-$ strongly disagree to 7 - strongly agree $)$ & Mean (SD) & CR & AVE \\
\hline $\begin{array}{l}\text { Competitive } \\
\text { pressure (Liang } \\
\text { et al., 2007) }\end{array}$ & $\begin{array}{l}\text { Our competitors have implemented marketing analytics to } \\
\text { collect, manage, and analyze data to extract useful insights } \\
\text { Our suppliers have implemented marketing analytics to collect, } \\
\text { manage, and analyze data to extract useful insights } \\
\text { Our customers have implemented marketing analytics to collect, } \\
\text { manage, and analyze data to extract useful insights }\end{array}$ & $\begin{array}{l}4.24(1.56) \\
4.02(1.58)\end{array}$ & 0.84 & 0.64 \\
\hline $\begin{array}{l}\text { Data availability } \\
\text { (Gupta and } \\
\text { George, 2016) }\end{array}$ & $\begin{array}{l}\text { We have access to very large, unstructured, or fast-moving data } \\
\text { for analysis } \\
\text { We integrate data from multiple internal sources into a data } \\
\text { warehouse or mart for easy access } \\
\text { We integrate external data with internal to facilitate high-value } \\
\text { analysis of our business environment }\end{array}$ & $\begin{array}{l}3.62(1.84) \\
3.59(1.75) \\
\end{array}$ & 0.84 & 0.64 \\
\hline $\begin{array}{l}\text { Managerial } \\
\text { perception } \\
\text { (Kearns and } \\
\text { Sabherwal, 2007) }\end{array}$ & $\begin{array}{l}\text { Top management team recognizes the strategic potential of } \\
\text { marketing analytics } \\
\text { Top management team is knowledgeable about marketing } \\
\text { analytics opportunities } \\
\text { Top management team is familiar with competitor's strategic } \\
\text { use of marketing analytics } \\
\text { Top management team believes marketing analytics contributes } \\
\text { significantly to firm performance }\end{array}$ & $5.11(1.48)$ & 0.89 & 0.68 \\
\hline
\end{tabular}

Managerial Top management team promotes the use of marketing analytics support in your company

(Chen et al., Top management team creates support for marketing analytics 2015, Liang et initiatives within your company al., 2007)

Top management team has promoted marketing analytics as a strategic priority within your company

$4.07(1.65) \quad 0.97 \quad 0.91$

Organizational We have the capital/financial resources to fully exploit readiness marketing analytics

(Iacovou et al., We have the needed IS infrastructure to fully exploit marketing 1995, Chen et al., analytics 2015)

We have the analytics capability to fully exploit marketing analytics

We have the skilled resources to fully exploit marketing analytics

$4.19(1.69)$

We implemented marketing analytics in customer insight

$3.71(1.70)$

Marketing
analytics use*
(CMO-Survey,
2016)

We implemented marketing analytics in customer acquisition

$3.49(1.52)$

We implemented marketing analytics in customer retention

$3.25(1.59)$

We implemented marketing analytics in customer segmentation 3.08 (1.60)

We implemented marketing analytics in new product or service development

$3.46(1.66)$

We implemented marketing analytics in product or service strategy

We implemented marketing analytics in promotion strategy

$3.47(1.66)$

We implemented marketing analytics in pricing strategy

$3.34(1.60)$

We implemented marketing analytics in marketing mix

$3.25(1.66)$

We implemented marketing analytics in branding

$3.26(1.63)$

We implemented marketing analytics in digital marketing

$3.63(1.67)$

We implemented marketing analytics in social media

$3.55(1.70)$

We implemented marketing analytics in multichannel marketing 2.92 (1.64) 
Table II. Configurations for the Presence of Marketing Analytics Use

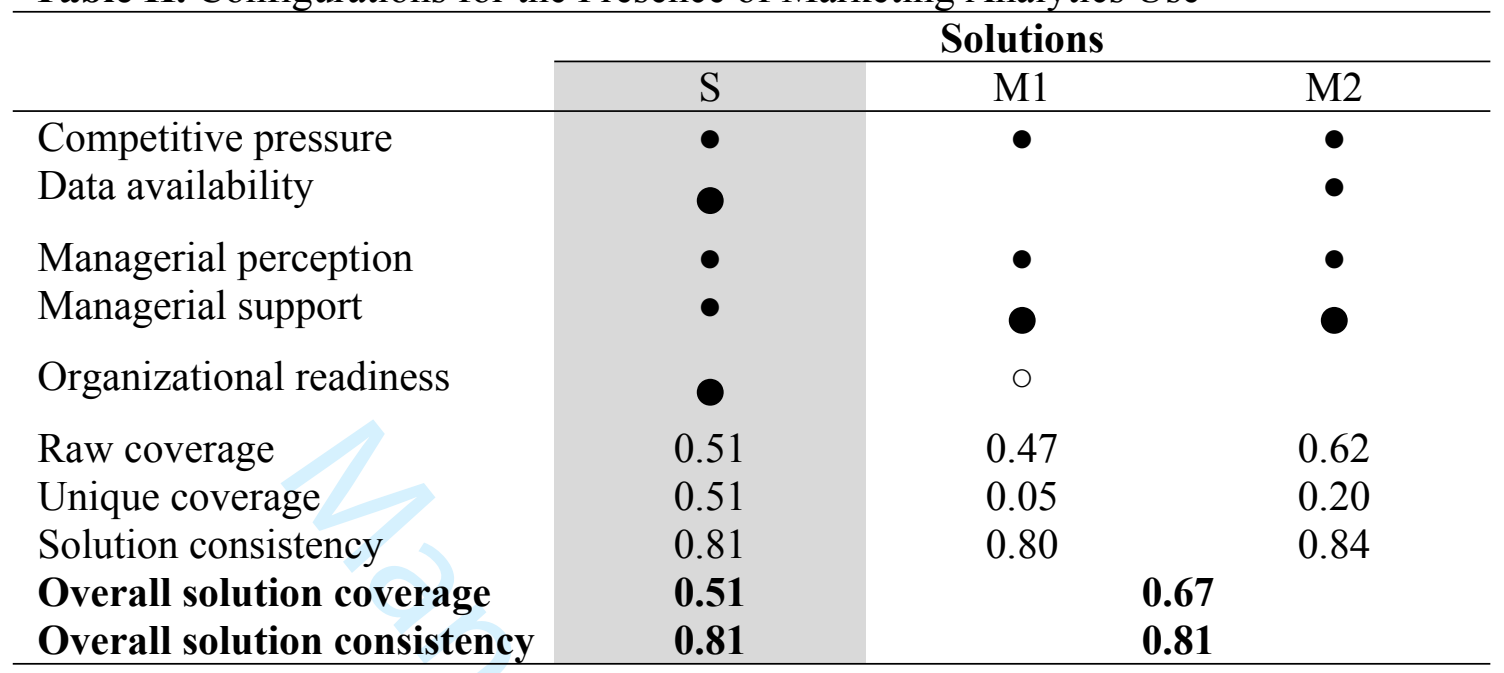

Note. = core causal condition present; $\bullet=$ peripheral causal condition present; $\bigcirc=$ peripheral causal condition absent

S-small firms; M-medium-sized firms

Table III. Configurations for the Absence of Marketing Analytics Use

\begin{tabular}{|c|c|c|c|c|c|c|c|}
\hline & \multicolumn{2}{|c|}{2} & \multicolumn{3}{|c|}{ Solutions } & \multirow[b]{2}{*}{ Ma2 } & \multirow[b]{2}{*}{$\mathrm{Ma3}$} \\
\hline & Sal & $\mathrm{Sa} 2$ & $\mathrm{Sa} 3$ & $\mathrm{Sa} 4$ & Ma1 & & \\
\hline Competitive pressure & & 0 & $\bullet$ & $\bullet$ & $\bullet$ & $\bullet$ & $\bullet$ \\
\hline Data availability & ० & o & o & & o & & ○ \\
\hline Managerial perception & o & & & $\bullet$ & O & $\bullet$ & \\
\hline Managerial support & O & 0 & 0 & $\bullet$ & O & $\bullet$ & 0 \\
\hline Organizational readiness & & O & $\bullet$ & $\bigcirc$ & & $\bigcirc$ & $\bigcirc$ \\
\hline Raw coverage & 0.45 & 0.33 & 0.29 & 0.32 & 0.34 & 0.32 & 0.32 \\
\hline Unique coverage & 0.09 & 0.03 & 0.03 & 0.13 & 0.08 & 0.14 & 0.02 \\
\hline Solution consistency & 0.96 & 0.98 & 0.97 & 0.84 & 0.98 & 0.77 & 0.96 \\
\hline Overall solution coverage & & & & & & 0.54 & \\
\hline Overall solution consistency & & & & & & 0.84 & \\
\hline
\end{tabular}

$\mathrm{O}=$ core causal condition absent; $\bullet=$ peripheral causal condition present; $\bigcirc=$ peripheral causal condition absent

$\mathrm{Sa}$ - absence of marketing analytics use in small firms; $\mathrm{Ma}$ - absence of marketing analytics use in medium-sized firms 